\title{
Perception of Abortion and Abortion Laws by Lawyers in Anambra State Nigeria
}

\author{
Chika F. Ubajaka1, Prosper 0. U. Adogu' ${ }^{*}$, Chitoo Ilika², Amobi L. Ilika1 \\ ${ }^{1}$ Department of Community Medicine and PHC, NAUTH, Nnewi, Nigeria \\ ${ }^{2}$ Department of Obstetrics and Gynecology, NAUTH, Nnewi, Nigeria \\ Email: "prosuperhealth@yahoo.com
}

Received 30 April 2014; revised 22 May 2014; accepted 12 June 2014

Copyright @ 2014 by authors and Scientific Research Publishing Inc.

This work is licensed under the Creative Commons Attribution International License (CC BY).

http://creativecommons.org/licenses/by/4.0/

(c) () Open Access

\begin{abstract}
Abortion is the knowing destruction of the life of an unborn child in the womb other than for the principal purpose of producing a life birth or removal of a dead tissue. The Nigeria law stipulates that abortion is allowed only where there is risk to the life of the woman and or to her physical or mental health. This study is aimed at determining the perception of abortion and the relevant laws by lawyers in Anambra State, Nigeria. It is a descriptive cross sectional study carried out between May-June 2010 using pre-tested self administered questionnaires to collect data from consenting 200 lawyers in the 3 major towns of Anambra State. All the respondents knew about abortion, recognized health hazards associated with it and mentioned infertility as the major complication of abortion (53\%) followed by death (52.5\%) and bleeding $(42.5 \%)$. About $80 \%$ of respondents said abortion should be allowed in cases of danger to woman's life, rape or incest. Eighty-five percent of the lawyers were aware of the existing abortion law in Nigeria and $76.5 \%$ of this knew abortion was legal only to save the life of the woman. Only $26 \%$ were in support of legalization of abortion. The Lawyers recommended health education and family planning, among others as means of preventing abortion and its complications. Stigma associated with abortion should be removed to improve free reporting of abortion cases for legal actions. Further research should involve other stakeholders on abortion to make for a holistic approach to the problem.
\end{abstract}

\section{Keywords}

Perception, Abortion Laws, Lawyers, Anambra State, Nigeria

\section{Introduction}

Abortion is the termination of pregnancy before the age of viability (28 weeks of gestation). It can also be de-

"Corresponding author.

How to cite this paper: Ubajaka, C.F., Adogu, P.O.U., Ilika, C. and Ilika, A.L. (2014) Perception of Abortion and Abortion Laws by Lawyers in Anambra State Nigeria. International Journal of Clinical Medicine, 5, 695-703.

http://dx.doi.org/10.4236/ijcm.2014.512095 
fined as the expulsion or extraction from its mother, a foetus or an embryo weighing 500 grams or less [1]. Abortion is said to be spontaneous when the pregnancy terminates on its own and is induced when the pregnancy is intentionally terminated [2]. Of the 210 million pregnancies that occur each year the world over, 80 million are unwanted, 46 million end in induced abortion and nearly 20 million are estimated to be unsafe resulting in the death of 80,000 women annually and 95\% of these occur in developing countries [3]. Studies have shown that a vast majority of women are likely to have at least one abortion by the time they are 45 years [4]. For every 1000 women of child bearing age, 35 are estimated to have an induced abortion. The major reason for induced abortion is unwanted pregnancy [3]. Pregnancies may not be wanted for social reasons like rape, teenage pregnancies, economic, cultural, and medical reasons [3]. This however varies amongst different population groups depending on socioeconomic status, religion, marital status, level of education as well as the fertility status of the woman. Abortion has moral, religious, cultural, human rights and public health implications. All of these interplay in the present state of affairs concerning abortion issues in the world.

An induced abortion may be legal or illegal. It is illegal if it is voluntarily done with intention to destroy the foetus. Where it is illegal, it constitutes a crime and may be committed any time before the natural birth of the child [5]. With only few exceptions, every country in the world permits abortion for at least some indication such as to save the woman's life, to terminate pregnancy resulting from rape or incest. Tragically even in countries with these exceptions, safe abortion is rarely openly available, accessible and affordable [6].

Here in Nigeria, at about the $19^{\text {th }}$ century, abortion before quickening was not regarded as an offence. After this stage, it was regarded as a common law misdemeanor. In 1803 procurement of abortion at anytime was made a statutory offence though only visited with capital punishment after quickening [2] Presently in Nigeria the term "abortion" is not legally defined under the criminal law. The synonym "procuring miscarriage" is used in the criminal code and penal code culled from the "offence against the persons" act of 1861 [5]. The criminal code is applicable mainly in Southern Nigeria and includes sections 228, 229, 230, 297, and 328 of the criminal code act [3] [5] while the penal code is applicable to Northern Nigeria and consists of sections 232, 233, 234, 235 and 236. Both the criminal and penal codes prescribe various forms of punishment ranging from fine to different terms of imprisonment for procurement of abortion.

To achieve the millennium development goal of reducing the level of maternal mortality by $75 \%$ by the year 2015, abortion which contributes $13 \%$ of all maternal deaths needs to be assessed and reviewed with attempts made at its eradication. The purpose of this study is to draw attention to this growing public health problem in the hope that the awareness will generate a concerted appropriate action by all stakeholders especially the lawyers to prevent abortion and reduce the morbidity and mortality associated with it. This study is important because lawyers are more likely to influence legislation on issues concerning abortion.

The specific objectives of this study include: 1) to determine the knowledge of abortion, its health risks and complications among the lawyers, 2) to assess the attitude of lawyers towards abortion and possible solutions to its complications and 3) to ascertain the role of socio demographic variables on their attitude towards abortion and abortion law in Nigeria.

\section{Methodology}

Study area: Anambra state is located in the South Eastern part of Nigeria. It is made up of 21 local government areas and several autonomous communities. There are however 3 major urban areas in the state and they are: Awka, Nnewi and Onitsha. Awka, the state capital, is situated in the heart of the state and presents a handful of opportunities, thus its population consists of both indigenes and non-indigenes majority of whom are civil servants. Nnewi town has 4 main villages Otolo, Uruagu, Umudim and Nnewichi. Nnewi is famed for industrialization, trading and banking. It has one federal teaching hospital, several public and private health facilities and many secondary schools. Onitsha is one of the biggest commercial towns located in Anambra state with trading as the major occupation of the people, perhaps because it has one of the largest markets in West Africa. It has a tertiary health centre, a general hospital, and numerous private hospitals.

Study population: The study population comprises of Lawyers from the three major towns Awka, Onitsha and Nnewi working in government and private establishments and are all brought together under one umbrella body which is the Nigerian Bar Association, Anambra state branch. The study population includes practicing lawyers.

Study design and sample size: The descriptive study design was used while the minimum sample size was 
calculated using the formula:

$$
n=\frac{z^{2} p q}{d^{2}}
$$

where $n=$ desired sample size, $z=$ standard normal deviate set at 1.96 which corresponds to $95 \%$ confidence level, $p=$ Prevalence of abortion [7] $=$ (use 15.1\%) $=0.151, q=1-p=0.749, d=$ degree of precision $(0.05)$.

$$
n=1.96^{2} \times 0.151 \times 0.749 / 0.05^{2}=0.6527301 / 0.0025=173.8 .
$$

Sampling technique: The study was a total population study of all Lawyers registered in the study area (Awka, Nnewi and Onitsha) and they are estimated to be 200 in number. All the Lawyers who gave their due consent were therefore recruited into the study. Note that the minimum sample size as determined above is meant to serve as a guide in the sense that the total study population of the respondents must necessarily be equal to or greater than the minimum sample size in order for the study outcome to remain valid and generalizable. Any Lawyer who was not yet registered with the professional body or who refused to participate in the study was excluded from the study.

Data collection: The self-administered questionnaires were distributed during the monthly meetings of the respondents and filled under supervision of the researchers. There were four sections in the questionnaire; the first section was meant to obtain information on bio-data and the other three sections designed to achieve the objectives of the study.

Data analysis: Data was analyzed using Statistical Package for Social Sciences (SPSS) version 19. Quantitative variables were summarized using appropriate measures of location and variability. Categorical variables were presented as frequencies and percentages. Bivariate analysis by use of the Chi-square test was employed to assess the significance of associations between agreeing to legalization of abortion and socio-demographic variables of the Lawyers. The level of significance was set at $\mathrm{p}<0.05$.

\section{Result}

Table 1 shows that out of the 200 respondents studied, 73 (36.5\%) were aged 20 - 30 years, 59 (29.5\%) were

Table 1. Socio-demographic variables of respondents.

\begin{tabular}{ccc}
\hline Socio-demographic variables & Frequency & Percentage \\
\hline Age group (years) & & 36.5 \\
$20-30$ & 73 & 29.5 \\
$31-40$ & 59 & 16.5 \\
$41-50$ & 33 & 17.5 \\
$>50$ & 35 & 100 \\
Total & 200 & 52 \\
Gender & & 48 \\
Males & 104 & 100 \\
Females & 96 & 35 \\
Total & 200 & 63 \\
Marital status & & 2 \\
Single & 70 & \\
Married & 126 & 48.5 \\
Divorced/separated & 4 & 36.5 \\
Religious denomination & & 15 \\
Roman catholic & 97 & 100 \\
Anglican & 73 & \\
Pentecostal & 30 & 200 \\
Total & &
\end{tabular}


aged 31 - 40 years, 33 (16.5\%) were aged 41 - 50 years while 35 (17.5\%) were older than 50 years. One hundred and four (52\%) were males while 126 (63\%) were married. Roman Catholics were in the majority.

Table 2 indicates that 30 (15\%) were aware of existing abortion laws in Nigeria and out of this, 23 (76.5\%) has good knowledge of the contents of the law. Bleeding, infertility, death and psychological trauma were listed by the lawyers as complications of abortion, while $2.5 \%$ thought carcinoma of the cervix, and infections were also complications of abortion.

Table 3 shows that $83.5 \%$ of the lawyers believe that abortion is an issue of unmarried girls who are promiscuous while $10 \%$ thought unfaithful wives will more likely seek abortion to conceal pregnancies from their promiscuity. One hundred and sixty-one (80.5\%) thought that abortion is justified when mother is ill or there is danger to mothers' life, $6.5 \%$ felt abortion should be allowed in cases of rape or incest, $6.5 \%$ said that fetal congenital abnormality is a reason for abortion, 3.5\% believed abortion should be offered to mentally deranged mothers while 3\% thinks that in cases of doubtful paternity, abortion should be allowed. Majority 75 (37.5\%) recommended that patients, teenagers should be educated on ways to prevent pregnancy in the first place \& avoid abortion, while 60 (30\%) recommended abstinence for single men \& woman as the panacea for preventing abortion.

In Table 4, 52 (26\%) of the Lawyers voted in favor of legalization of abortion while 137 (68.5) were against legalization. Also 192 (96\%) does not engage in abortion cases in court while only a few (4\%), entertain abortion cases in their chambers. Majority, 152 (79.2\%) of the 192 who do not entertain cases of abortion in their chambers said abortion cases were not brought to them while the rest reject such cases on grounds of principles, 15 (7.8\%), faith, 15 (7.8\%) and belief, 10 (5.2\%).

Table 5 shows that the support for legalization of abortion reduces as increase in the age of the lawyers. The younger Lawyers are statistically significantly more likely to vote for legalization of abortion than their older counterparts $(\mathrm{p}<0.02)$. There is no significant difference in the support for legalization of abortion along gender and religious denomination variables of the Lawyers.

Figure 1 show that the most cited (25\%) reason by the Lawyers for supporting abortion is that it will remove stigma and shame thereby allowing the women to seek help from skilled personnel rather than quacks. On the other hand, a greater majority (30.5\%) believe that abortion is not good, should be stopped and completely abolished.

Table 2. Lawyers' awareness and knowledge of abortion and its complications.

\begin{tabular}{ccc}
\hline Awareness & Frequency & percent \\
\hline $\begin{array}{c}\text { Aware of abortion law } \\
\text { Unaware of abortion law }\end{array}$ & 30 & 15 \\
Total & 170 & $\mathbf{1 0 0}$ \\
Has knowledge of content of law (among the aware) & $\mathbf{2 0 0}$ & 76.5 \\
Has no knowledge of content of law (among the aware) & 23 & 23.5 \\
Total & 7 & $\mathbf{1 0 0}$ \\
Health complications & $\mathbf{3 0}$ & Percentage \\
Bleeding & Frequency & 42.5 \\
Infertility & 85 & 53 \\
Death & 106 & 52.5 \\
Psychological Trauma & 105 & 23.5 \\
Others & 47 & 2.5 \\
\hline
\end{tabular}

NB: Both frequency and percent columns add up to more than expected 200 and $100 \%$ respectively because multiple answers were indicated. 
Table 3. Lawyers' opinion on likely abortion seekers, justifications and prevention for abortion.

\begin{tabular}{|c|c|c|}
\hline Likely abortion seeker & Frequency & Percentage \\
\hline Unmarried girls because of their promiscuity & 167 & 83.5 \\
\hline Couples who refuse to use family planning & 4 & 2 \\
\hline Unfaithful wives to conceal pregnancies & 20 & 10 \\
\hline Couples who have completed their families & 8 & 4 \\
\hline Couples with poor socioeconomic status. & 1 & 0.5 \\
\hline Total & 200 & 100 \\
\hline Justifications & Frequency & Percentage \\
\hline Rape/ incest & 13 & 6.5 \\
\hline Mother is ill/danger to mother's life & 161 & 80.5 \\
\hline Fetal abnormality & 13 & 6.5 \\
\hline Mentally deranged mother & 7 & 3.5 \\
\hline Doubtful paternity & 6 & 3 \\
\hline Total & 200 & 100 \\
\hline \multicolumn{3}{|l|}{ Recommendations on prevention of abortion } \\
\hline 1) Government should provide abortion centers and train doctors on the procedures & 20 & 10 \\
\hline $\begin{array}{l}\text { 2) Patients, teenagers educated on ways to prevent pregnancy } \\
\text { in the first place } \& \text { avoid abortion }\end{array}$ & 75 & 37.5 \\
\hline 3) Family planning, counseling and promotion of contraceptive to avoid pregnancy & 45 & 22.5 \\
\hline 4) Abstinence for single men \& woman & 60 & 30 \\
\hline Total & 200 & 100 \\
\hline
\end{tabular}

Table 4. Lawyers' opinion on legalization and engagement in abortion cases in court.

\begin{tabular}{lcc}
\hline & Frequency & Percentage \\
\hline For Legalization & 52 & 26 \\
Against Legalization & 137 & 68.5 \\
Neutral & 11 & 5.5 \\
Total & 200 & 100 \\
Engagement in abortion cases in court Engages in abortion case in court & 8 & 4 \\
Does not engage in abortion case in court & 192 & 96 \\
Total & $\mathbf{2 0 0}$ & $\mathbf{1 0 0}$ \\
Reasons for not engaging in abortion cases in court (for those 192 who do not engage) & & 79.2 \\
No one has come to me & 152 & 7.8 \\
It is against my faith & 15 & 7.8 \\
I don't want to be involved with abortion & 15 & 5.2 \\
My establishment does not allow such cases & 10 & $\mathbf{1 0 0}$ \\
Total & $\mathbf{1 9 2}$ & \\
\hline
\end{tabular}


Table 5. Socio-demographic variables of Lawyers and legalization of abortion.

\begin{tabular}{ccccccc}
\hline Age group & Legalize & $\%$ & Not Legalize & $\%$ & $\mathrm{X}^{2}$ & $\mathrm{p}$-value \\
\hline $20-30$ & 26 & 50 & 43 & 31.4 & & \\
$31-40$ & 19 & 36.5 & 33 & 24.1 & 16 & $\mathrm{p}<0.02$ \\
$41-51$ & 4 & 7.7 & 30 & 21.9 & & \\
$>50$ & 3 & 5.8 & 31 & 22.6 & & \\
Total & 52 & 100 & 137 & 100 & & \\
Gender & & & & & \\
Male & 24 & 46.2 & 70 & 51.1 & & \\
Female & 28 & 53.8 & 67 & 48.9 & 0.36 & $\mathrm{p}$ \\
Total & 52 & 100 & 137 & 100 & & \\
Denomination Roman Catholic & 20 & 38.5 & 69 & 50.4 & & \\
Anglican & 20 & 38.5 & 52 & 37.9 & 4.44 & $\mathrm{p}>0.05$ \\
Pentecostal & 12 & 23 & 16 & 11.7 & & \\
Total & 52 & 100 & 137 & 100 & \\
\hline
\end{tabular}

Note: Total number of respondents for legalize and not legalize were 189 and not 200 because 11 respondents were neutral on this issue (see Table 4).

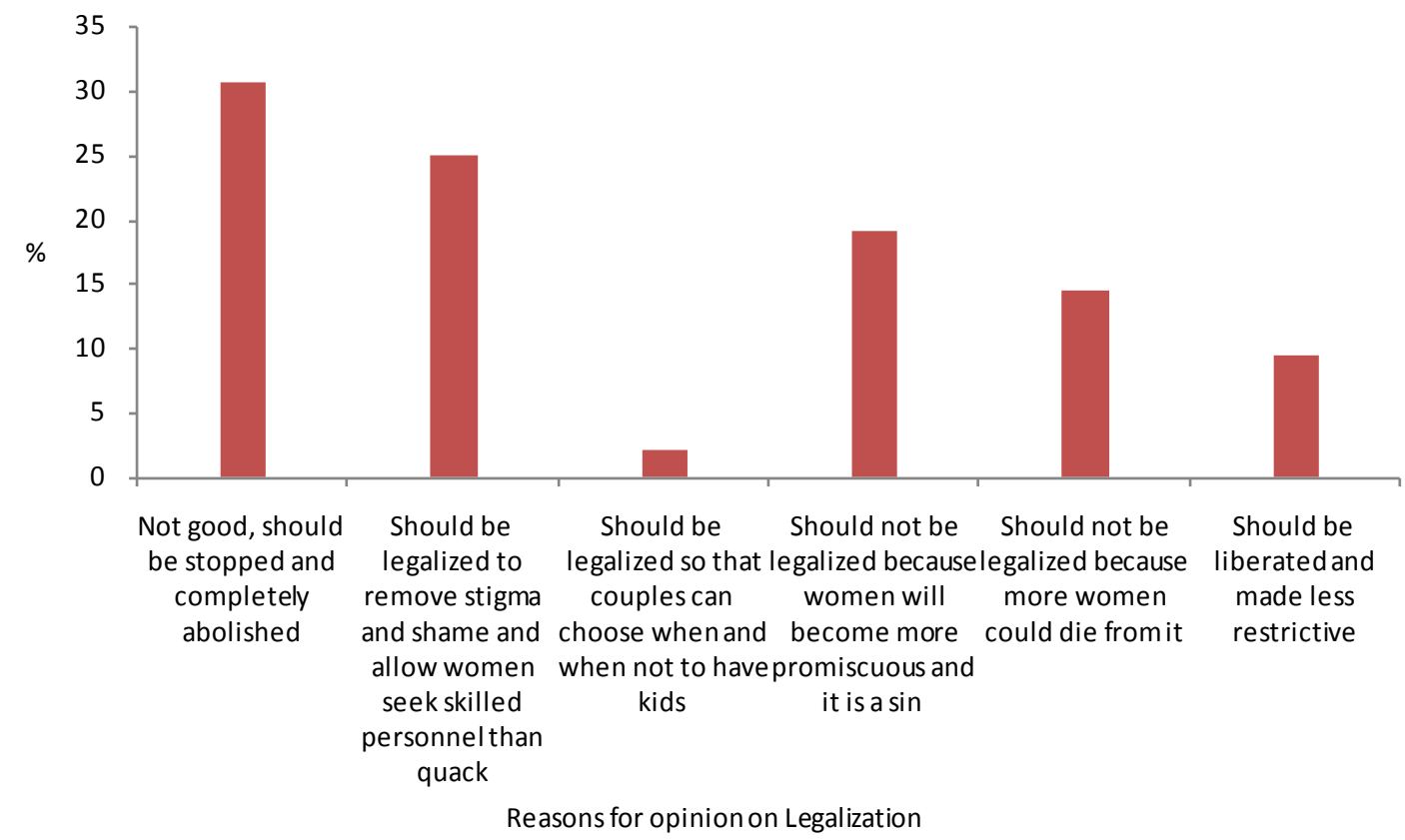

Figure 1. Reasons for Lawyers’ opinion on legalization of abortion.

\section{Discussion}

This study was designed to explore the attitudes and perceptions of Lawyers in Nigeria regarding abortion and the country's abortion law. With Nigeria's current legal and political system, the national law and related policies can be reviewed on a comprehensive scale at the national level only by the national assembly. However, opportunities for legal reform also exist at the state level and a pronouncement in a case before the high court could provide an additional avenue for a legal amendment. All the lawyers in this study knew what abortion was and 
they all acknowledged that there was health risk associated with it. Infertility was the health complication of abortion most commonly cited while other complications in decreasing order of frequency were death, bleeding, psychological trauma and carcinoma of the cervix and infections. Lawyers had an idea of the occurrence of abortion in our society as opposed to the study by Okonofua F.E. among policy makers where they had poor knowledge of the number of abortions occurring in Nigeria [8].

Out of the 200 lawyers, $120(60 \%)$ had come in contact with abortion victims or had people who came to seek their opinion to procure an abortion. Twenty (16.7\%) of the 200 lawyers had committed abortion, 9 (7.2\%) of the lawyers had wives who had committed abortion, 5 (4.2\%) of them had daughters who had committed abortions and others had sisters, friends, relations and clients who had committed abortions. These findings further emphasize the increasing alarming rate of abortion in our society even among the elites, and justify the conclusion by Inegbenebor Ute in Edo state in a study among teenagers that although abortion is restricted in Nigeria, it is widely practiced [9]. The reasons for the abortion in the above cases included: Unwanted pregnancy, health reasons, fetal congenital abnormality and rape. This agrees with the outcome of a study by Adinma J.I.B. et al. which stated that unwanted pregnancy is the commonest cause of abortion in our environment [3], just as the result of a study by Okonofua F.E. showed that $100 \%$ of the respondents believed that women resorted to unsafe abortion when they had unwanted pregnancy [8].

This study demonstrated that only 35\% of Lawyers knew people who had died from abortion as opposed to the findings of another study by Okonofua F.E. where majority of the subjects knew people who had died or nearly died of abortion [8]. Furthermore, $20 \%$ of the respondents felt that abortion is bad and should never be allowed. This figure is lower than, though comparable with that reported among policymakers where one third of them believe that abortion should not be allowed under any circumstance [8]. Majority of those who thought abortion should be liberalized in some cases gave danger to mother's life or mother's illness as the major circumstance where abortion should be allowed. This is followed by rape or incest, fetal congenital anomaly, mentally deranged mother and the case of doubtful paternity was the last mentioned. These situations are in consonance with those cited in other studies done in Nepal and Trinidad \&Tobago, where the respondents believed that incest, rape and danger to a woman's life were the most important reasons for which abortion should be permitted [10] [11]. Similarly in the study by Okonofua F.E., 20\% of the subjects thought it should be liberalized on medical grounds while $20 \%$ also voted for rape or incest [8].

A large proportion of the Lawyers (83.5\%) felt that unmarried girls will more likely seek abortion due to their promiscuity. This agrees with the result of study done by Kasule et al. in Zimbabwe among health professionals where all respondents agreed that majority of women who present for abortion are single [12]. Also in the study by Azmat S.K. et al. in Pakistan among Law professionals, all believe that most abortion clients were unmarried [13]. However, this does not seem to agree with the findings of Konney T.O. et al. in Ghana that only $29 \%$ of the women admitted with abortion complications were unmarried [14]. However, $10 \%$ of the lawyers in our study believed that unfaithful wives will more likely seek abortion to conceal pregnancies resulting from their unfaithful encounters. This is similar to the study by Lawoyin T.O. et al. in Ibadan where the male respondents claimed that unfaithful couples and those who refused to use family planning were more likely to seek abortions [15].

Most (70\%) of the lawyers believed that abortion concerns both the man and the woman involved. This is rather surprising because it is in contradistinction to the general belief that abortion is a woman's problem and that men have no role to play in it. The high literacy level of respondents in this study could explain their strong positive perception about men's involvement in abortion matters.

On the existing abortion law in Nigeria, despite the fact that $85 \%$ of the lawyers were aware of such laws, $76.5 \%$ of this group knew that abortion was legal only to save the life of the mother while $23.5 \%$ were not conversant with the details of the abortion law. Moreover, while $96 \%$ of the lawyers have neither seen nor engaged in any abortion case in court, $79 \%$ of this group said it was because no abortion case has been reported to them, neither has anyone come to them for advocacy. This finding emphasizes the fact that though abortion is widely practiced, yet the cases are underreported and the law rarely practiced. This situation is not peculiar to Nigeria alone since another study by Azmat S.K. et al. in Pakistan revealed that most cases of abortion are unreported and settled outside of the formal court [13]. Abortion cases are largely unreported and settled outside the formal court and the abortion law is rarely practiced in Nigeria as almost all the respondents have not seen or been engaged in any abortion case in court. This ice berg phenomenon associated with criminal abortion is most likely linked to stigmatization. Even in medical circles, the word "abortion" is mentioned with caution because of the 
stigma associated with the condition. For fear of being misunderstood, many medical practitioners prefer the use of the term "miscarriage" in an attempt to paint a picture of a "normal" obstetric accident thus increase its acceptability among the people. The existing Nigerian abortion law may remain moribund for a long time until the stigmatization associated with it is completely removed.

The fact that only $26 \%$ voted for legalization of abortion, and 5.5\% were non-committal in their response is similar to the result of study done by Okonofua F.E. in Nigeria where few supported legalization of abortion. Another study done by Lawoyin T.O. in Ibadan among men also found just 8.2\% supporting legalization of abortion [15]. However, this does not agree with the study by Inegbenebor Ute in Edo state among teenagers seeking abortion, where $80 \%$ voted for legalization of abortion [9]. Also in a similar study by Orji E.O among undergraduates, $80 \%$ supported legalization of abortion [16]. The findings in the last two studies cited might be due to the youthful age and single marital status of the respondents. More than $85 \%$ of them were aged 20 to 40 years of age and so would more likely favor abortion. The significant inverse relationship $(\mathrm{p}<0.02)$ between age of Lawyers and support for legalization of abortion as found in our study is a further testimony that youthful age is a strong predictor of support for legalization of abortion.

The fact that female Lawyers who support legalization in this study made up 53.9\% of those who supported legalization (as opposed to the $46.1 \%$ who were male supporters), is an indication that women carry the burden of pregnancy and may need an abortion at some point. More than half (50.4\%) of those who opposed legalization of abortion are Roman Catholics. This is not surprising as the Catholic Church is strictly against issues of abortion and contraception. The Lawyers frowned at legalization of abortion because they felt this could debase the people's moral and religious values leading to sin against God. Also they were more worried that abortion legalization will engender promiscuous life style among women, than for the fact that they could die from it.

Majority of the Lawyers suggested sex education, family planning, promotion of contraceptive use, abstinence as ways to prevent pregnancy and avoid abortion and its complications and these are strong indications of unfavorable perception of abortion and abortion laws by the Lawyers. This view is further reinforced by the finding that majority (50\%) of them voted against legalization of abortion. However $10 \%$ still believes that provision of abortion centres by the government and training of doctors on the procedure is the solution to the problem. The Lawyers have good knowledge of abortion and its occurrence in our society, recognize health hazards associated with it and singled out infertility as the major complication of abortion followed by death, bleeding, psychological trauma, and others. This knowledge is more likely based on what they read from news media and other literature than on personal life encounter with affected persons. However, they have poor knowledge of abortion related deaths.

A minority (20\%) of the respondents believes that abortion is bad and should never be allowed in any circumstance while the rest thinks it should be allowed especially when there is danger to mother's life or in cases of rape or incest. This is similar to the findings of another study in Trinidad \& Tobago in which majority of respondents cited incest, rape and danger to a woman's life as the most significant circumstances under which abortions should be permitted. Most of the lawyers believe that abortion is a problem of the unmarried rather than the married and they are not only aware of the existing abortion law in Nigeria but also have a good grasp of the details of the provisions of the law. Yet abortion is common and widely practiced in our environment and unwanted pregnancy remains the major reason why it is practiced in our society.

\section{Conclusion and Recommendations}

Unsafe abortion and its complications remain issues that are better prevented than cured; proper sex education and counseling on reproductive health should be added to the curriculum of primary and secondary school children to prevent bad sex habit and avoid pregnancy in the first place. Proper parenting and adequate parental communication especially with the adolescent children will help boost their confidence and improve their ability to negotiate sex and withstand peer pressure. Government should embark on economic empowerment and education especially of the young girls, to keep them busy and protected from sexual harassment by men. Advocacy for abstinence among single girls and boys to prevent unwanted pregnancy; schools and religious leaders will be encouraged to take up the role to teach their congregations about the benefits of chastity and consequences of immorality. Family planning should be promoted among married people at all levels with proper counseling to enable them make the right choice of the method most convenient for them. There is need for the government to regulate the activities of health facilities and chemist shops to eliminate quackery. The stigma often associated with abortion must be removed to improve its reporting and enhance application of the existing relevant laws 
enacted to moderate the practice of abortion, thereby preventing the complications associated with criminal abortion. While pursuing the noble objective of prevention of abortion, government and private health facilities should also be equipped with post abortion care facilities to help check complications of abortion. Finally, there is need for more research and use of common case identifiers to determine the knowledge and perceptions of other stakeholders and draw the attention of people to this problem of abortion.

\section{Ethical Consideration}

The purpose of the research was explained to the lawyers and their consent obtained before distribution of questionnaires. They were assured of confidentiality on all information given. NAUTH Institutional ethical clearance was also obtained before the study was conducted.

\section{Conflict of Interests}

No conflict of interests declared by the authors.

\section{Funding}

The article was funded by the researchers themselves.

\section{References}

[1] Ikpeze, O.C. (2009) Fundamentals of Obstetrics and Gynecology. 1st Edition, Africana First Publishers PLC, Onitsha, 177.

[2] Ilika, A.L. (2005) A Handbook of Adolescent Health for Young People and Stakeholders. 1st Edition, St. Stephen's Press, Onitsha, 19-20.

[3] Adinma, J.I.B., et al. (2007) Unsafe Abortion: An Unacceptable Tragedy of Our Time. Women's Sexual and Reproductive Rights News, 6, 2-19.

[4] (2003) Safe Abortion: Technical and Policy Guidance for Health System. World Health Organization, Geneva.

[5] Ogiamen, T.B.E. (2000) Abortion Law in Nigeria: The Way Forward. Women's Health and Action Research Centre, Benin, 1-4.

[6] Hord, C.E. (2001) Making Safe Abortion Accessible: A Practical Guide for Advocates. 1st Edition, Chapel Hill, USA, 3-9.

[7] Akinola, O.I., Fabamwo, A.O., Tayo, A.O., Alokha, M., Oshodi, Y.A. and Bamidele, O.O. (2010) Unsafe Abortion and Post Abortion Care: Patients Profile and Perceptions in Lagos, Nigeria. Research Journal of Medical Sciences, 4, 170174. http://dx.doi.org/10.3923/rjmsci.2010.170.174

[8] Okonofua, E.F., Hammed, A., et al. (2009) Perceptions of Policymakers in Nigeria towards Unsafe Abortion and Maternal Mortality. International Perceptions on Sexual and Reproduction Health, 35, 194-202.

[9] Inegbenebor Ute (2010) Prevention of Abortion Dependent Maternal Mortality in Nigeria. http://www.weathat.com/plugin/print/

[10] Martin, C.J., Hyacinth, G. and Suite, L.S. (2007) Knowledge and Perception of Abortion and the Abortion Law in Trinidad and Tobago. Reproductive Health Matters, 15, 97-107. http://dx.doi.org/10.1016/S0968-8080(07)29301-2

[11] Singh, M. and Jha, R. (2007) Abortion Legalized: Challenges Ahead. Kathmandu University Medical Journal, 5, 9597.

[12] Kasule, J. and Mbizvo, M.T. (1999) Abortion: Attitude and Perception of Health Professionals in Zimbabwe. Central African Journal of Medicine, 45, 239-244.

[13] Azmat, S.K., Mohsima, B., et al. (2009) Perspective and Understanding of Law Professionals towards the Abortion Law and Women Rights to Safe Abortion in Pakistan. A Poster Presentation in the 5th Asia Pacific Conference on Reproductive and Sexual Health and Rights, Beijing, 17-20 October 2009.

[14] Konney, T.O., Danso, K.A. and Odoi, A.T. (2009) Attitude of Women with Abortion Related Complications towards Provision of Safe Abortion Services in Ghana. Journal of Women's Health, 18, 1863-1866. http://dx.doi.org/10.1089/jwh.2008.1190

[15] Lawoyin, T.O., Adewale, D.A., et al. (2007) Men’s Perception of Maternal Mortality in Nigeria. Journal of Public Health Policy, 28, 299-318. http://dx.doi.org/10.1057/palgrave.jphp.3200143

[16] Orji, E.O. and Adeyemi, A.B. (2003) Liberalization of Abortion Laws in Nigeria: The Undergraduates' Perspective. Journal of Obstetrics and Gynecology, 23, 63-66. http://dx.doi.org/10.1080/0144361021000043281 
Scientific Research Publishing (SCIRP) is one of the largest Open Access journal publishers. It is currently publishing more than 200 open access, online, peer-reviewed journals covering a wide range of academic disciplines. SCIRP serves the worldwide academic communities and contributes to the progress and application of science with its publication.

Other selected journals from SCIRP are listed as below. Submit your manuscript to us via either submit@scirp.org or Online Submission Portal.
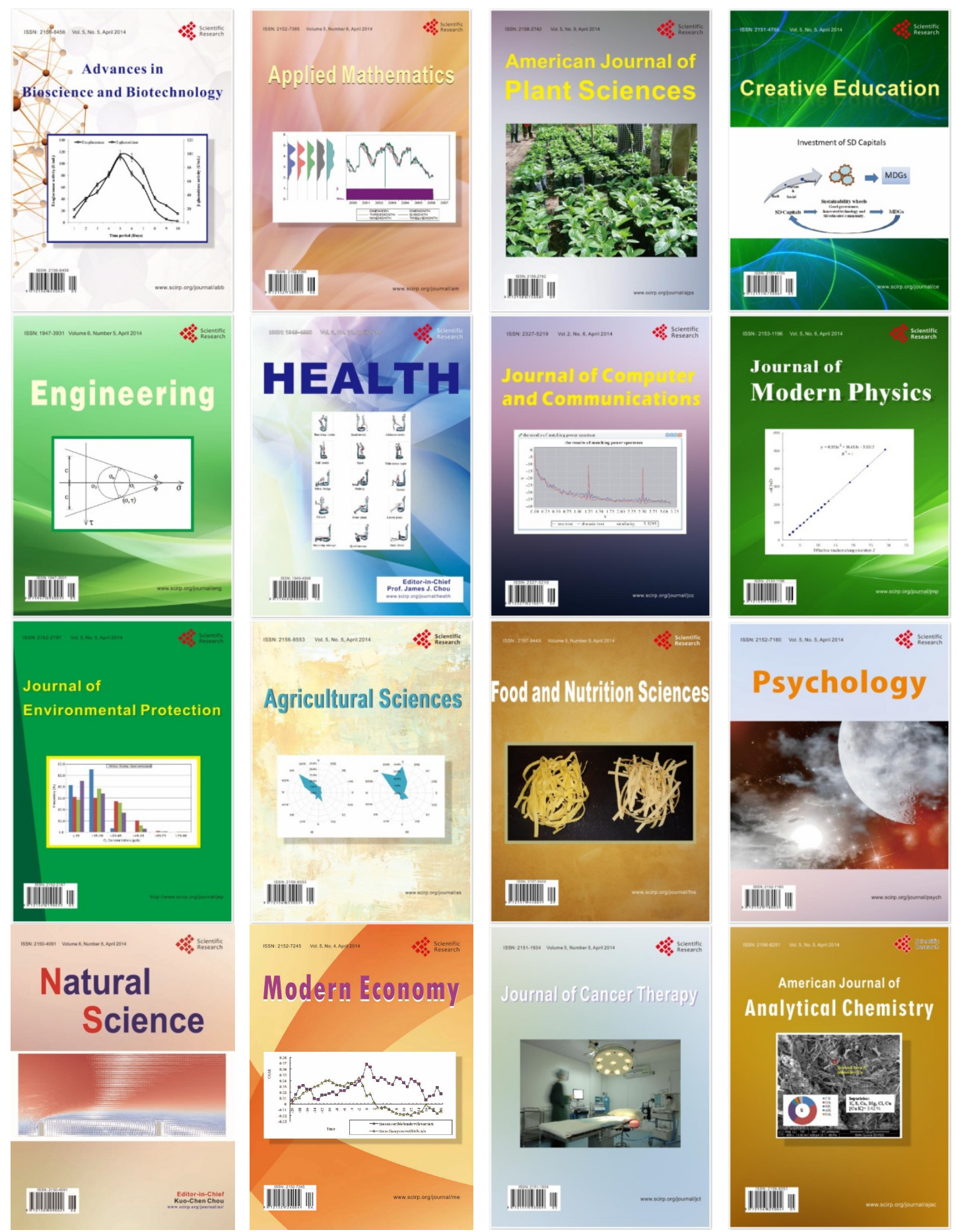